\title{
The Effect of the Reader Response Approach on Secondary School EFL Students' Reading Comprehension of Narrative Texts
}

\author{
Dr\ Reham Ahmed Youssef, \\ Ministry of Education, Egypt, \\ yreham47@gmail.com
}

\begin{abstract}
The present study aimed to introduce an alternative method for teaching the novel in Egyptian secondary schools. Teachers stated that there is no agreed upon method for teaching stories and novels. In addition, there is no Teacher Guide for teaching the novel provided by the Ministry of Education. Therefore, this study aimed at investigating the Effect of the Reader Response Approach (RRA) on Egyptian Secondary School EFL Students' Reading Comprehension of narrative texts. For this purpose, the researcher designed a Program to teach the novel: Gulliver's Travels based on the Reader Response Approach. One group comprising 35 Egyptian female students at a secondyear secondary school participated in the study. A Reading Comprehension test was used to measure their comprehension of the novel at three comprehension levels. Results indicated the effectiveness of the Reader Response Approach in enhancing students' reading comprehension and critical thinking. This finding proves that the RRA program had a significant impact on the participants' overall reading skills.
\end{abstract}

Keywords: Reader Response Approach, EFL Reading Comprehension, Narrative Texts, EFL Literature

\section{Introduction}

In recent years, there has been a growing interest in utilizing literature in foreign language (FL) and second language (SL) classrooms [1]. Recent research explains the various benefits of using literature in L2 learning [2]. Literature provides L2 learners with a combination of pleasurable, comprehensible, authentic linguistic input and a low affective filter [3].

Literature provides L2 students with authentic sociolinguistic input and a low affective filter. Literature provides authentic samples of text-types and registers. Moreover, literature presents a rich authentic source of learning new words, new expressions, and grammatical structures [4].

Believes using literature in the EFL/ESL classroom is in line with Communicative Language Teaching (CLT) principles. Literature encourages student-cantered activities and collaborative group work .[5]
Pedagogic Principles underlying the Reader Response Approach Research on using literature in EFL teaching and learning indicates that the Reader Response Approach (RRA) is a pedagogically effective approach to teaching literature [6].

The RRA is based on the transactional theory of reading which stresses the active role of the reader in constructing meaning. She argues that what the student brings to the reading process is as important as the literary text itself. According to Rosenblatt, a transaction is a two-way process involving a reader and a text at a particular time under particular circumstances. The reader brings his/her personal experience, knowledge, emotions and cultural values, and "transacts" with the text. That is why every reader may have his/her interpretation of the text. In other words, there are multiple interpretations of the text. [7] RRA emphasizes the creative role of the reader [8]. 
RRA stimulates readers to create meaning through activating their schema about the topic. Besides, they arouse their intentions, moral values and life experiences. RRA gives students chances to be free in expressing their ideas in nonthreatening classroom environments [9].

using RRA in language teaching has several benefits:

a) Encourages multiple interpretations of texts

b) Enriches classroom discussions

c) Enhances autonomous learning

d) Encourages students to express their opinions and feelings

e) Promotes spontaneous speaking and free writing

f) Let's students listen to others' opinions and respect them.[10]

\section{Related Studies}

conducted a study to determine the effects of literature circles on the reading comprehension and reading fluency of fourth grade Turkish EFL students. and to reveal readers' responses in this process. Literature circles method was used in the quantitative dimension of the study, whereas the Reader Response was used in the qualitative dimension. Treatments were carried out in two separate classes on the fourth grade of primary school one of which was the experimental group and the other was control group. Multiple choice reading comprehension test was used to determine the students' reading comprehension and a multidimensional fluency scale was used to evaluate reading fluency as data collection tools. Reader responses were revealed through an open-ended questionnaire. Results showed that the literature circles method had positive effects in terms of reading comprehension. On the other hand, it was observed that the literature circles method had positive effects in terms of reading speed in the narrative and informative texts. Analysis of qualitative data obtained from the reader responses to the books they read, revealed that the answers of the students to the books they read were mostly reader cantered. From the first literature circle to the last literature circle application, it was also noticed that the reader-cantered responses increased, and text-cantered responses decreased in each literature circle during the treatment.[11]

conducted a study to determine if the use of written Reading Response activities would improve reading comprehension when students are reading independently. The study was conducted with twenty 3 rd grade students. The students read one text a week for ten weeks and completed written reading response activities before, during, and after reading each text. The reading responses focused on the comprehension strategies of predicting, questioning, visualizing, and summarizing. The goal was for the students to build the metacognitive skill of comprehension monitoring and use the reading strategies when independently reading. Data was collected from teacher created rubrics from the reading responses, comprehension quizzes for each text read, and reading comprehension test scores. Analysis of the data showed a positive effect size of the use of reading responses on reading comprehension when reading independently.[12] investigated the effect of collaborative Reader Response on promoting students' critical thinking skills. Participants were 24 Indonesian university EFL students studying (Critical Reading and Writing) course. Students worked in groups with different roles: leaders, word wizards, inspectors, and navigators. They read the texts with different purposes in mind, and they shared what they learnt from the text to the group. After group discussion, they created posters and presented them to friends in the class. These reader response activities encouraged students not only to interpret the writers' purposes in creating the text, but they also created meaning by using their background knowledge when interacting with the text. In this case, readers were encouraged to play an active role in interpreting the meaning of the texts. Data were collected from classroom observations, online archives and students' written reflections. Analysis of data showed that the Reader Response Approach enhanced students' critical thinking skills as well as their critical reading skills. [13] conducted a qualitative study to investigate the effect of the Reader-Response Approach on Indonesian EFL students reading comprehension of narrative texts and their attitudes towards it. Instruments used in the study were: observation checklist, field notes, transcription, and reflective documents. Spoken and written activities based on the RRA were used in the study. These activities incorporated "Engaging, Describing, Conceiving, Explaining, Connecting, Interpreting" strategies during the teaching and learning process. Furthermore, students made "Interpretive, Affective, Reflective" responses while reading the texts. Results indicated the effectiveness of the RRA in enhancing students' critical reading comprehension of narrative texts. In addition, students reported positive attitudes towards the RR method indicating that it encouraged them to reflect on events from different perspectives.[14]

investigated quantitatively the effect of the reader-response approach on EFL learners' reading comprehension, retention of vocabulary and test anxiety. Fifty-two Iranian students participated in the study for seven consecutive weeks in twenty sessions. The participants were divided into two groups: experimental and control. In the experimental group, the readerresponse approach was used. Students were asked to read specific pages of the story at home. The teacher provided students with the following questions to guide them through their reading:

1. What struck you about the story?

2. What kinds of things did you notice?

3. What would you like to talk about after reading this?

4. What issues did it raise for you? Were there parts that confused you?

5. What questions would you like to ask?

6. Did anything upset you or make you angry?

7. Is there anything you want to ask about any of the characters?

8. How did you feel after you read the story?

9. What made you feel this way? [15]

During the treatment, the students were reminded that there was not just one correct interpretation to the questions, and there could be as many correct interpretations as possible. The researcher used three instruments: Language Test, Vocabulary 
Test and Anxiety Scale. Two short stories were used in both groups: "Little Women" by Louisa May Alcott and "Galliver's Travel" by Jonathan Swift. Surprisingly, there were no significant differences between the two groups with reference to: reading comprehension achievement and vocabulary retention. Interestingly, it was found that students' anxiety in the experimental group was significantly reduced.

used the RRA to investigate its effect on EFL Pre-Service Teachers' reading of literary texts. The study was mainly qualitative. Nine advanced EFL Colombian students participated in the study. Using the RRA, they read two authentic English stories. The treatment lasted 16 weeks. Two instruments were used in the study to collect data were:

1. Reflection reports in which students wrote their reflections after reading the literary texts and collected them in a portfolio.

2. Classroom discussions after reading the literary texts.

3. Interviews.

The researchers noticed that oral group and class discussions encouraged reluctant readers to read and reflect on the events and characters in the story in relation to their real life. In general, most students stated that they enjoyed using RRA because it helped them bring their inner feelings, emotions and personal lives in the reading process. They also indicated that this approach encouraged them to speak freely without hesitation. In addition, the RRA motivated them to write freely about their personal lives. [16]

discussed the benefits of the application of reader-response theory in EFL literature classes at a teacher education college in Indonesia. The study aimed to improve student teachers' qualitative accounts of their aesthetic experiences and English as a Foreign Language (EFL) competence. Instruments used in the study included the use of video-recorder, which was operated by a selected collaborator, to capture the subjects' psychological reflections and physical involvements as portrayed in classroom participation. Results indicated that reader response-based instruction resulted in the students' higher self-confidence and fluency in using the target language. Their improvement in selfconfidence and language growth can be revealed from both spoken and written discourses. [17]

used the RRA to investigate the effect of the RRT on the second year secondary Omani students' comprehension of short stories and their attitudes towards the method used in teaching short stories. Two instruments were used in this study: a reading comprehension test and a questionnaire. The questionnaire was used to elicit student's attitudes towards the method used in teaching the story. Students were asked to read the story and reflect on the events and the characters' actions and write their reflection in their logs. Analysis of the students' logs indicated that:

1. Through the RRT the students began to make personal connections between literature and their lives and the world.

2. Through the classroom discussion, students learnt to accept other students' opinions and interpretations.

3. The tasks asking the students to react to different characters provided an excellent opportunity for the discussion of characters. Students were eager to justify why they had reacted in certain ways towards the characters.

4. The tasks allowed the students to discuss and write about issues that interested them. Students gained insight about other societies and cultures. Moreover, students reported that they gained clearer understanding of the ideas in the story. [18]

\section{Methodology}

Hence, the present study aims to investigate the effect of the Reader Response Approach on secondary school female students' reading comprehension of novel.

\section{Hypotheses}

1. There is a statistically significant difference at 0.01 level between the mean score in the pre and post administration of the overall reading test in favor of the post administration.

2. There is a statistically significant difference at 0.01 level between the mean score in the pre and post administration of the literal comprehension skills in favor of the post administration.

3. There is a statistically significant difference at 0.01 level between the mean score in the pre and post administration of the referential comprehension skills in favor of the post administration.

4. There is a statistically significant difference at 0.01 level between the mean score in the pre and post administration of the critical comprehension skills in favor of the post administration.

Design The present study adopted a quasi-experimental pre-post one-group design. The group received instruction in RRA basedprogram.

Participants One second- year class was selected randomly from The Old Secondary Experimental Language School for Girls in Kafr-El-Sheikh Governorate. The class comprised 35 students. Almost all of them were 17 year olds. They were also similar regarding their economic, social and schooling background.

Instrument A pre-post Reading Comprehension test was used in the study. It comprised three reading passages. After each passage, there are six reading questions. The reading questions may be multiple-choice questions, open-ended questions, or true and false questions.

\section{Aims of the Reading Test}

In accordance with the English syllabus objectives, the test assessed some reading comprehension skills at three main levels as follows:

1) Literal comprehension skills

a. Recognizing explicit main ideas.

b. Identifying explicit information and details.

c. Identifying time and sequence.

2) Inferential comprehension skills

a. Inferring implied main ideas.

b. Inferring implied meaning.

c. -Guessing the meaning of words from context.

3) Critical comprehension skills 

a. Identifying relationships between ideas.
b. Identifying the overall organizational pattern.
c. Identifying the reader's opinion.

\section{Validity of the Reading-Writing Test}

The preliminary version of the test was submitted to a jury of TEFL experts and English language senior teachers and supervisors who had long experience in teaching English in secondary schools in general and teaching second year students in particular. They were given instructions to check the validity of the test in terms of :-

a) The suitability of the reading comprehension texts to students' level

b)The suitability of the item to the stated skill

c) The sufficiency of items to cover the identified skills

d)The clarity of the test items and instructions

In light of the jurors' comments, the following modifications were made:

a) The reading texts were shortened.

b) Some items were reassigned as measuring different subskills.

\section{Piloting the Test:}

The test was piloted on a random sample of students (28) other than the sample of the study. The test was piloted in order to:

a) Measure its reliability.

b) Measure item difficulty, easiness and discrimination.

c) Estimate the time allotted for completing the test.

In the light of the students' responses:

a) Some ambiguous words were replaced

b) The optimum time for completing the test was set.

c) The reading texts were shortened

\section{Test Reliability}

The split- half method was used to obtain the reliability of the test. The Pearson

Product-Moment Correlation Coefficient (r) was .07. This

\section{Materials} shows that the test was reliable.

\section{Teacher's Guide}

The major aim of this guide was to familiarize the teacher with reference to:

a) Benefits of using literature in teaching and learning English.

b) Explanation of the Reader Response Approach.

c) The objectives of using RRA in the treatment

d) Teaching procedures

e) The role of the teacher

f) The role of students

g) Formative and summative assessment techniques.

\section{The Reader Response Approach Program Aims}

1. Familiarize students with:

a) Benefits of using literature in learning English

b) The Reader Response Approach

2. Introduce Gulliver's Travels novel to students:

a) Present a short introduction about the author Jonathan

Swift

b) Present a short summary of the novel

3. Present content and teaching steps of each session
4. Discuss new vocabulary and grammatical structures in the novel

5. Present reading comprehension activities with reference to literal, inferential and critical levels.

6. Practice group work.

7. Present formative and summative assessment activities.

\section{Results}

\section{The first hypothesis:}

There is a statistically significant difference at 0.01 level between the mean score in the pre and post administration of the overall reading test in favor of the post administration.

In order to verify this hypothesis, the researcher compared the pretest mean score to that of the posttest mean score on the overall reading and writing performance test. The researcher used t. test for dependent group to determine the significance of the difference between the pre-test and posttest. Table (1) below shows the results.

Table (1) T-Test Result for The Difference Between the Mean Scores Of the Pre-Post Total Reading Test:

\begin{tabular}{|c|c|c|c|c|c|c|c|}
\hline Variable & & $\mathrm{N}$ & $\mathrm{M}$ & SD & $\mathrm{df}$ & $\mathrm{t}$ & Sig \\
\hline \multirow{2}{*}{$\begin{array}{l}\text { Total } \\
\text { Reading }\end{array}$} & Post & 35 & 12.26 & 1.094 & \multirow[t]{2}{*}{34} & \multirow[t]{2}{*}{5.104} & .00 \\
\hline & Pre & 35 & 10 & 2.378 & & & 0 \\
\hline
\end{tabular}

Table (1) shows that the posttest mean score $(M=12.26)$ is higher than the pretest mean score $(M=10)$ and there is a statistically significant difference $(\mathrm{t}=5.10)$ at .01 level. This proves that the RRA program had a significant impact on the participants' overall reading skills. Therefore, hypothesis one is verified.

\section{The second hypothesis}

There is a statistically significant difference at 0.01 levels between the mean score in the pre and post administration of the literal comprehension skills in favor of the post administration. Table (2), below, shows that the posttest mean score for literal comprehension $(\mathrm{M}=4.6)$ is higher than the pretest mean score $(\mathrm{M}=3.14)$ and there is a statistically significant difference $(\mathrm{t}=3.67)$ at .01 level. This proves that the RRA program had a significant impact on the participants' literal comprehension reading skills. Therefore, hypothesis one is verified.

\section{The third hypothesis}

There is a statistically significant difference at 0.01 level between the mean score in the pre and post administration of the referential comprehension skills in favor of the post administration. Table (2) also shows that the posttest mean score for inferential comprehension $(M=5.03)$ is higher than the pretest mean score $(\mathrm{M}=4.5)$ and there is a statistically significant difference $(\mathrm{t}=1.99)$ at .01 level. This proves that the RRA program had a significant impact on the participants' inferential comprehension reading skills. Therefore, hypothesis one is verified. 


\section{The fourth hypothesis}

There is a statistically significant difference at 0.01 level between the mean score in the pre and post administration of the critical comprehension skills in favor of the post administration. Table (2) also shows the posttest mean score for critical comprehension ( $\mathrm{M}=3.37)$ is higher than the pretest mean score $(M=2.63)$ and there is a statistically significant difference $(\mathrm{t}=3.13)$ at .01 level.

Table (2) t-test result for the difference between the mean scores of the pre-post Reading levels

\begin{tabular}{|l|l|l|l|l|l|l|l|}
\hline Reading & & $\mathrm{N}$ & $\mathrm{M}$ & $\mathrm{SD}$ & $\mathrm{df}$ & $\mathrm{t}$ & Sig. \\
\hline Literal & Post & 35 & 4.60 & 1.333 & 34 & 3.679 & .001 \\
\cline { 2 - 6 } & Pre & 35 & 3.14 & 2.427 & 34 & & \\
\hline Inferential & Post & 35 & 5.03 & .954 & 34 & 1.999 & .054 \\
\cline { 2 - 6 } & Pre & 35 & 4.51 & .951 & 34 & & \\
\hline Critical & Post & 35 & 3.37 & .910 & 34 & 3.138 & .004 \\
\hline & pre & 35 & 2.63 & 1.00 & 34 & & \\
\hline
\end{tabular}

These results, shown in Table (2), prove that the RRA program had a significant impact on the participants' reading comprehension at all levels.

\section{Discussion}

The results indicate the effectiveness of the RRA program. These results may be attributed to the effect of the types of reading questions and activities. The reading questions and activities did not focus on literal content of the novel. In other words, these questions required students to construct new meanings and express their own interpretations of the events and characters' behaviors. They encouraged students to reflect critically on their life, cultural values and personal experiences. The reading questions and activities provided students with rich input. The group and class oral discussions of these questions and activities provided students with authentic opportunities to listen to different meaningful interpretations and points of views. During the sessions, the teacher continually reminded the students that there was not just one correct interpretation to the questions, and there could be as many acceptable interpretations as possible.

This, in turn, lessened their reluctance to express their ideas freely and raised their self-confidence level with reference to their reading ability. Moreover, the reading activities encouraged students to think, compare and accept others' views.

\section{Conclusion}

In conclusion, the present research shows that using literature in teaching English as a foreign or second language gives students the chance to re-examine their beliefs, thinking, and life. Literature provides L2 students with a combination of pleasurable, authentic sociolinguistic input and a low affective filter. It offers authentic samples of a very wide range of styles, registers, and text-types. It provides students with meaningful opportunities to reflect on concepts, recognize real life problems, explore causes and solutions, and compare their values and life styles with other cultures. Moreover, literature presents a rich authentic source of learning new words, new expressions, and grammatical structures. Students show increase in vocabulary size and awareness of the interrelationships among words.

These results are consistent with the results of (Biglari and Farahian 2017), Garzón and Castañeda-Peña (2015) and Nafisah (2014).

\section{References}

[1] Amer, A. (2003). Teaching EFL/ESL Literature. The Reading Matrix, 3, 2, 69-70.

[2] Hess, N. (2006). The short story: Integrating language skills through the parallel life approach. In A. Paran (Ed.), Literature in language teaching and learning (pp. 27-43). Alexandria, Vermont: Teachers of English to Speakers of Other

[3] Krashen, S. D. (2004). The power of reading. Portsmouth, New Hampshire: Heinemann Publishing Company.

[4] Duff, Alan, and Maley, A. (2007). Literature (2nd). Oxford: Oxford University Press.Ekstam, J. (2018). Metacognition and Reader Response: the use of reading logs in the envisionment-building classroom. Acta Didactica Norge, 12, 2, pp. 1-27.

[5] Van, T.T.M. (2009). The relevance of literary analysis to teaching literature in the EFL classroom. English Teaching Forum, 3, pp. 2-9

[6] Amer, A. (2012). Using literature in reading English as Foreign or Second language. ERIC (ED528593)

[7] Rosenblatt, Louise M. (1995). Literature as exploration (5th Ed.). New York: The Modern Language Association.

[8] Carlisle, A. (2000). „Reading logs: an application of reader-response theory in EFL' ${ }^{\text {e. }}$ ELT Journal, 54, 1, 12-19.

[9] Iskhak, S. (2013). Catering for students' needs to promote aesthetic experience in EFL literature class with reference to response centered curriculum. CELT (A journal of culture, English language teaching and literature), 13.1, 66-86.

[10] Ekstam, J. (2018) «Metacognition and Reader Response: the use of reading $\operatorname{logs}$ in the environment-building classroom», Acta Didactica Norge, 12(2), s. Art. 7, 27 sider. (doi: 10.5617/adno.6093.)

[11] Tosun, D. K., \& Dogan, B. (2020). The Effects of Literature Circles on Reading Fluency, Reading Comprehension and Reader Responses: A Mixed Method Study. Education and Science, 45, 203, 153176.

[12] Wilkinson, C. (2019). Boosting Reading Comprehension through Response Activities. Master of Education, Northwestern College, Iowa, USA.

[13] Pasaribu, T., and Iswandari, Y. (2018). A Reader Response Approach in Collaborative Reading 
Projects to Foster Critical thinking Skills. LLT Journal, Vol. 22, No. 2, pp. 231-245.

[14] Ningrum, C, H. (2018). The Use of Reader-Response Theory to Teach Reading Narrative Text for Tenth Graders of Senior High School. Retain. 6, 2018, 95103.

[15] Biglari,N. and Farahian, M. (2017). An Investigation into the Effect of Reader Response Approach on EFL Learners' Reading Comprehension, Vocabulary Retention and Test Anxiety. Theory and Practice in Language Studies, 7, 8, pp. 633-643.

[16] Garzón, H. and Castañeda-Peña1, H. (2015). Applying the Reader-Response Theory to Literary Texts in EFL-Pre-Service Teachers' Initial Education. English Language Teaching. 8, 8, pp. 187-198.

[17] Iskhak (2015). The Application of Reader-response Theory in Enhancing Student Teachers' Affective and Linguistic Growth: A Classroom Action Research in EFL Teacher Education in Indonesia. The English Teacher, XLIV (2), 43-55.

[18] Al-Bulushi, Y. (2011). Teaching Short Stories in the Omani Context: The Use of the Reader Response Theory. Literacy Information and Computer Education Journal (LICEJ), 2, 3, 450-455.

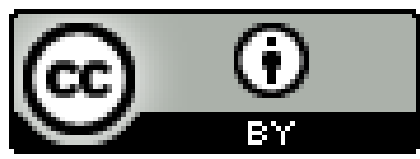




\section{Appendix (1)}

\section{Activities for writing and oral discussion}

\section{Activity 1}

There has been a great argument between the two main political groups:

the Tramecksan and the Slamecksan.

In your own words, explain the reasons behind the conflict and its effect on the country. Can you think of a practical solution to this conflict?

\section{Activity 2}

Imagine you were the ambassador to Liliput and Blefusco. Write a letter to the kings of the two countries to advise them to end the conflict between the two countries. Explain to them the benefits the two countries might gain from being friends in commerce, tourism, construction, etc.

\section{Activity 3}

Imagine you were in a land where everybody and everything were so big. What advantages would you have? What disadvantages would you face? Would you be happy? Write as many ideas as you can.

\section{Activity 4}

Some people say that Gulliver's Travels is a children novel. Other people say it is a novel for adults. Discuss this argument with your group members and write a report expressing your opinion. 


\section{Appendix (2)}

\section{Examples of reflective questions}

1. If you were in X's position, would you act similarly? Explain.

1. In your opinion, was X's behavior/action appropriate? Why?

2. Is Y's acceptable in our culture? Explain.

3. What character do you like most? Why?

4. Write a summary of the chapter in your own words.

5. Write a paragraph about the main character from your point of view.

6. Do you like the RRA? Explain the benefits you gained from this new method.

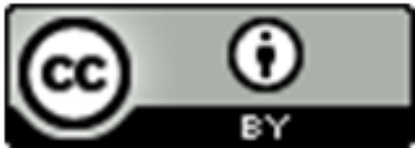

